\title{
Uptake of HIV testing and outcomes within a Community-based Therapeutic Care (CTC) programme to treat Severe Acute Malnutrition in Malawi: a descriptive study
}

\author{
Paluku Bahwere*1, Ellen Piwoz ${ }^{\dagger 2}$, Marthias C Joshua ${ }^{\dagger 3}$, Kate Sadler ${ }^{\dagger 1}$, \\ Caroline H Grobler-Tanner ${ }^{\dagger 2}$, Saul Guerrero ${ }^{\dagger 1}$ and Steve Collins ${ }^{\dagger 1}$
}

Address: ' Valid International, Unit 9, Standingford House, 26 Cave Street, Oxford, OX4 1BA, UK, ${ }^{2}$ Academy for Educational Development, Washington DC, USA and ${ }^{3}$ Ministry of Health, Dowa District Hospital, PO Box 25, Dowa, Malawi

Email: Paluku Bahwere* - paluku@validinternational.org; Ellen Piwoz - Ellen.Piwoz@gatesfoundation.org; Marthias C Joshua - dowahmis@malawi.net; Kate Sadler - kate@validinternational.org; Caroline H Grobler-Tanner - cgroblertanner@yahoo.com; Saul Guerrero - saul@validinternational.org; Steve Collins - steve@validinternational.org

* Corresponding author †Equal contributors

Published: 31 July 2008

BMC Infectious Diseases 2008, 8:106 doi:10.1186/147/-2334-8-106

This article is available from: http://www.biomedcentral.com/I47I-2334/8/106

(C) 2008 Bahwere et al; licensee BioMed Central Ltd.

This is an Open Access article distributed under the terms of the Creative Commons Attribution License (http://creativecommons.org/licenses/by/2.0), which permits unrestricted use, distribution, and reproduction in any medium, provided the original work is properly cited.
Received: 15 August 2007

Accepted: 31 July 2008

\begin{abstract}
Background: In Malawi and other high HIV prevalence countries, studies suggest that more than $30 \%$ of all severely malnourished children admitted to inpatient nutrition rehabilitation units are HIV-infected. However, clinical algorithms designed to diagnose paediatric HIV are neither sensitive nor specific in severely malnourished children. The present study was conducted to assess : i) whether HIV testing can be integrated into Communitybased Therapeutic Care (CTC); ii) to determine if CTC can improve the identification of HIV infected children; and iii) to assess the impact of CTC programmes on the rehabilitation of HIV-infected children with Severe Acute Malnutrition (SAM).

Methods: This community-based cohort study was conducted in Dowa District, Central Malawi, a rural area 50 $\mathrm{km}$ from the capital, Lilongwe. Caregivers and children admitted in the Dowa CTC programme were prospectively (Prospective Cohort $=\mathrm{PC}$ ) and retrospectively (Retrospective Cohort $=\mathrm{RC}$ ) admitted into the study and offered HIV testing and counseling. Basic medical care and community nutrition rehabilitation was provided for children with SAM. The outcomes of interest were uptake of HIV testing, and recovery, relapse, and growth rates of HIV-positive and uninfected children in the CTC programme. Student's t-test and analysis of variance were used to compare means and Kruskall Wallis tests were used to compare medians. Dichotomous variables were compared using $\mathrm{Chi}^{2}$ analyses and Fisher's exact test. Stepwise logistic regression with backward elimination was used to identify predictors of HIV infection $(\alpha=0.05)$.
\end{abstract}

Results: 1273 and 735 children were enrolled in the RC and PC. For the RC, the average age (SD) at CTC admission was 30.0 (17.2) months. For the PC, the average age at admission was 26.5 (13.7) months. Overall uptake of HIV testing was $60.7 \%$ for parents and $94 \%$ for children. HIV prevalence in severely malnourished children was $3 \%$, much lower than anticipated. $59 \%$ of HIV-positive and $83 \%$ of HIV-negative children achieved discharge Weight-For-Height (WFH) $\geq 80 \%$ of the NCHS reference median $(p=0.003)$. Clinical algorithms for diagnosing HIV in SAM children had poor sensitivity and specificity.

Conclusion: CTC is a potentially valuable entry point for providing HIV testing and care in the community to HIV infected children with SAM. 


\section{Background}

Access to prophylactic cotrimoxazole and to timely initiation of antiretroviral therapy can tremendously improve the survival of HIV infected children [1-5]. HIV testing is the "gateway" or first step to introducing infected children to these interventions[6]. Unfortunately, the coverage of HIV testing still remains low in most resource constrained countries, particularly for children, and existing pediatric clinical algorithms have low sensitivity for detecting HIV, particularly among the severely malnourished $[7,8]$. Thus, most HIV-infected children remain undiagnosed, even in households with an adult already on antiretroviral treatment (ART)[9].

Reasons for low coverage of pediatric testing are varied but include high postnatal dropout from Prevention of Mother-to-Child Transmission (PMTCT) programmes, and relatively few testing facilities, especially in rural areas $[10,11]$. In 2005, Malawi had an estimated 91,000 HIV infected children ( $\leq 14$ years) [12]. Among them, the cumulative number on ART by March 2006 was 2718, representing only $3.0 \%$ of all infected children and 5.8\% of patients on ART in Malawi to date [12].

The HIV epidemic is contributing to increased child mortality and severe malnutrition throughout Africa $[13,14]$. In Malawi and elsewhere where HIV is highly prevalent, studies suggest that $30 \%$ or more of all children admitted to inpatient nutrition rehabilitation units are HIVinfected [13,15-17]. A prior study in Malawi demonstrated that many HIV-infected children with severe acute malnutrition (SAM) can achieve an adequate Weight-ForHeight (WFH) with appropriate therapeutic feeding, although recovery times are significantly longer and mortality is much higher compared to HIV-uninfected children [18]. Unfortunately in Africa, the low coverage of both HIV testing and therapeutic feeding and the multiple factors preventing caregivers bringing children to hospital and remaining with them for extended periods $[7,19,20]$ means that the majority of all HIV-infected African children do not receive any nutritional care. Thus, it is important to find innovative ways of identifying HIV-infected children, especially those from remote areas, to allow them to benefit from cotrimoxizole prophylaxis, nutritional care, and ARV treatment in developing countries.

Community-based Therapeutic Care (CTC) is an approach for managing SAM in children $<5$ years that provides care close to where people live and focuses on early detection of SAM through community mobilization [21]. Children with appetite and without complications are managed directly in the community in an Outpatient Therapeutic Programme (OTP) and provided with routine medical care and nutrient-dense, pathogen resistant Ready-to-Use Therapeutic Foods (RUTF) for nutritional rehabilitation [22] on a weekly basis. Children with generalized severe oedema, anorexia and medical complications are treated at inpatient facilities according to national protocols, until they are stabilized and appetite has returned and they are able to rejoin the OTP $[23,24]$. Children are discharged from the OTP when they achieve WFH $\geq 80 \%$. Previous evaluations show that CTC achieves high coverage and has lower default and mortality rates compared to traditional therapeutic feeding programs $[25,26]$. Throughout Africa, home-based care programs are providing support for HIV-affected households. We undertook this study to identify appropriate ways of diagnosing HIV among malnourished children and to assess the feasibility and outcome of treating severely malnourished HIV-infected children in a community based program. This paper presents the uptake of HIV testing when integrated within an ongoing CTC programme, the comparative outcomes of HIV-infected and uninfected malnourished children enrolled in the programme and the diagnostic value of anthropometric and other admission characteristics for identifying children at risk of HIV where diagnostic testing is not available.

\section{Methods}

The study was carried out from December 2002 to May 2005 in the Dowa district of central Malawi, where antenatal and adult HIV prevalence were estimated to be $9.8 \%$ and $6.4 \%$, respectively $[27,28]$ Voluntary HIV Counselling and Testing (VCT) was offered to caregivers and children who were enrolled or had recently graduated from a CTC programme run by the Ministry of Health and the non-governmental organization Concern Worldwide. Clinical records were reviewed to assess our primary outcomes: HIV testing uptake and test results and indices of nutritional recovery in HIV-infected and uninfected children. Two groups of caregivers were invited to participate: 1) those who were discharged from CTC prior to VCT introduction (retrospective cohort), and 2) those who entered CTC after testing was introduced (prospective cohort).

\section{Retrospective Cohort (RC)}

Traditional leaders, Health Surveillance Assistants (HSAs), and community volunteers were responsible for locating recent programme graduates using CTC discharge records. Caregivers were visited at home to explain the study objectives and procedures and to invite them to bring their children to the next recruitment day. A verbal autopsy was carried out for children who had died since leaving the programme [27]. Only families of children presently residing in the geographic catchment areas of the 17 health centres providing CTC in Dowa district were contacted. At recruitment, VCT was offered to children and their caregivers. Pre and post-test counselling was carried out by trained nurses and HSAs in accordance with 
guidelines from the Malawi Ministry of Health for HIV testing and counselling of adults and children $<13$ years [28].

Outcomes of interest from the RC include: 1) HIV testing uptake and outcome; 2) nutritional recovery whilst in the CTC programme (weight gain, change in Mid Upper Arm Circumference, time to recovery); and 3) mortality and change in nutritional status from CTC discharge to recruitment. Clinical data were extracted from an electronic database and individual programme monitoring cards.

\section{Prospective cohort (PC)}

Procedures were similar for the PC children except that VCT was offered at admission to the programme. All PC children were treated according to standard CTC protocols and children whose caregivers chose not to join the study were not treated any differently. Children were recruited into the study from 29/11/2004 to 09/04/2005 corresponding to the 2004/2005 hunger period ( $70 \%$ of annual admissions are usually observed during the hunger season). The outcomes of interest of the PC were the same than that of the RC with 2 exceptions: 1) we could calculate mortality and programme default (children who left the programme prior to achieving $>85 \%$ of median WFH); 2) data on follow up after discharge were unavailable.

\section{Data collection}

At admission to the study, a clinical assessment and history was obtained for each child by one of three trained nurses using a structured data collection tool. The history included ascertainment of the signs and symptoms used for clinical diagnosis of paediatric HIV in algorithms used by WHO [29,30] and Action against Hunger (AAH) [31] [Table 1] and identification of the presence of any proxy indicator commonly used in Malawi to indirectly identify individuals infected or affected by HIV/AIDS when blood testing it is not possible or appropriate [32]. Baseline nutritional assessments included weight and height, MUAC, and presence or absence of bilateral, pitting oedema [21,33-35]. Information on the parents' vital status was also obtained.

\section{Standardisation and quality control of clinical data}

A pilot study to train and standardize the nurses in the collection of clinical data was conducted prior to commencing the RC. The principal researcher $(\mathrm{PB})$, a paediatrician with experience in managing HIV infected children, carried out the training and the standardization process. He also provided daily supervision of the 3 nurses during the first month and twice weekly thereafter. The supervision included examination of 2 randomly selected children per nurse and comparing the paediatrician findings and the nurse findings. Finally, all the data collected by the nurses were checked in the office by the paediatrician for consistency prior to data entry. The 3 trained nurses collected data at enrolment in the RC and admission and follow up data for the PC.

\section{HIV testing procedures}

HIV sero-status in adults and children $>12$ months was ascertained via antibody testing from finger-prick blood samples using a serial algorithm with Determine ${ }^{\circledR}$ as first test and Unigold ${ }^{\circledR}$ as a confirmatory test [36,37]. For discordant results, Bioline ${ }^{\circledast}$ rapid test was used as the tiebreaker. For children $<12$ months, whole blood HIV DNA polymerase chain reaction (PCR) testing was used (Roche Amplicor Version 1.5). Children between 12 and 18 months were tested using the same algorithm as for older children, but positive antibody results were confirmed by PCR since maternal antibodies may persist in infant blood for up to 18 months $[38,39]$. Rapid test results were given to caregivers within one hour of the test. PCR test results were provided within 2 weeks. Caregivers' uptake and HIV test results presented in the present papers concern only biological parents of the child.

\section{Treatment provided}

Children were treated using standard CTC protocol. Children with SAM without complications were directly admitted into OTP. Children in both cohorts were provided with Vitamin A, de-worming, anaemia treatment, antibiotics for bacterial infections, and malaria prophylaxis according to standard CTC protocols [33]. For the $\mathrm{RC}$, children found to be anaemic (haemoglobin $<11 \mathrm{~g} /$ dl) received the standard Malawian IMCI anaemia treatment and were referred to the nearest health centre for continuation of treatment and follow up. Children with severe anaemia (Haemoglobin $<6 \mathrm{~g} / \mathrm{dl}$ ) were referred to the district hospital for appropriate management. RUTF (200 kcal $/ \mathrm{kg} /$ day) was provided as weekly take-home rations. During the $\mathrm{RC}$ recruitment a protection ration was given to households of admitted children. No protection ration was given during the PC recruitment. All HIVpositive children were referred to the Lighthouse Project in Lilongwe, which provides comprehensive paediatric HIV care following national guidelines. HIV-positive adults were referred to the Dowa District Hospital Antiretroviral Therapy (ART) clinic.

\section{Statistical analyses}

Data analyses were carried out using Epi-Info 6.04 [40] and SPSS for Windows Version 12 [41]. Daily weight gain ( $\mathrm{g} / \mathrm{kg} /$ day) was calculated as the difference between the weight (in grams) at discharge and the weight (in grams) at admission (RC) or lowest weight recorded during participation in CTC (PC), divided by weight at admission (in kilograms) multiplied by number of days in the programme. Changes in MUAC and WFH were determined 
Table I: Clinical algorithms for diagnosing paediatric HIV

\begin{tabular}{|c|c|c|c|}
\hline \multirow[t]{2}{*}{ Algorithm } & \multicolumn{2}{|c|}{ Variables } & \multirow[t]{2}{*}{ Diagnostic Criteria } \\
\hline & History & Physical findings & \\
\hline \multirow[t]{11}{*}{$\begin{array}{l}\text { Original IMCl } \dagger \text { Algorithm for } \\
\text { Paediatric HIV }\end{array}$} & $\begin{array}{l}\text { - Chest infection requiring hospital } \\
\text { admission in the past } 3 \text { months }\end{array}$ & - Weight below $3^{\text {rd }}$ centile & $\begin{array}{l}\text { - Classify as suspected } \\
\text { symptomatic HIV infection if } 3 \\
\text { positive findings }\end{array}$ \\
\hline & $\begin{array}{l}\cdot>=2 \text { episodes of diarrhea in the } \\
\text { past } 3 \text { months }\end{array}$ & $\begin{array}{l}\text { - Poor weight gain } \\
\text { (growth monitoring card) }\end{array}$ & \\
\hline & $\begin{array}{l}\text { Episode of persistent diarrhea } \\
\text { (lasting } 14 \text { days) in the past } 3 \\
\text { months }\end{array}$ & $\begin{array}{l}\text { - Any enlarged lymph glands in } \\
\text { more than one of the following } \\
\text { sites: neck, axillary or groin }\end{array}$ & \\
\hline & - Fever $>=$ I month & $\begin{array}{l}\text { - Oral thrush extending to the } \\
\text { back of the mouth or throat }\end{array}$ & \\
\hline & - Poor appetite & & \\
\hline & - Chronic ear infection (14 days) & & \\
\hline & $\begin{array}{l}\text { - History or evidence of past or } \\
\text { present herpes zoster }\end{array}$ & & \\
\hline & $\begin{array}{l}\text { - History or evidence of severe } \\
\text { seborrheic dermatitis }\end{array}$ & & \\
\hline & - History of past or present TB & & \\
\hline & $\begin{array}{l}\text { - Parent or sibling known to have } \\
\text { TB }\end{array}$ & & \\
\hline & $\begin{array}{l}\text { - Parent or sibling known to be } \\
\text { HIV-positive }\end{array}$ & & \\
\hline \multirow[t]{4}{*}{$\begin{array}{l}\text { Improved IMCI Algorithm } \\
\text { (South Africa adaptation) }\end{array}$} & - Pneumonia today§ & - Weight below $3^{\text {rd }}$ centile & $\begin{array}{l}\text { - Classify as suspected } \\
\text { symptomatic HIV infection if } 3 \\
\text { positive findings }\end{array}$ \\
\hline & - History of weight loss $\mathbb{T}$ & $\begin{array}{l}\text { - Poor weight gain } \\
\text { (history or RTH card) }\end{array}$ & \\
\hline & $\begin{array}{l}\text { - Persistent diarrhea now or in } \\
\text { past } 3 \text { months }\end{array}$ & $\begin{array}{l}\text { - Any enlarged lymph glands in } \\
\text { more than one of the following; } \\
\text { neck, axillae or groin }\end{array}$ & \\
\hline & - Ear discharge now or in the past & $\begin{array}{l}\text { - Oral thrush } \\
\text { - Parotid swelling }\end{array}$ & \\
\hline \multirow[t]{10}{*}{$\begin{array}{l}\text { Action Against Hunger } \\
\text { Algorithm }\end{array}$} & - Ear discharge now or in the past & & $\begin{array}{l}\text { - When child presents with }>=3 \\
\text { criteria refer for further HIV } \\
\text { support/care and health education }\end{array}$ \\
\hline & - Enlarged lymph glands now & & \\
\hline & $\begin{array}{l}\text { - Pneumonia today or persistent } \\
\text { cough }>\text { I month }\end{array}$ & & \\
\hline & - Persistent diarrhea & & \\
\hline & - Low weight gain & & \\
\hline & - Oral thrush & & \\
\hline & $\begin{array}{l}\text { - Marasmus or Marasmus/ } \\
\text { Kwashiokor }\end{array}$ & & \\
\hline & - Fever for more than one month & & \\
\hline & $\begin{array}{l}\text { - Child is an orphan } \\
\text { (one or both parents) }\end{array}$ & & \\
\hline & $\begin{array}{l}\text { - Child's parents are sick or one of } \\
\text { siblings has died }\end{array}$ & & \\
\hline
\end{tabular}

$\dagger \mathrm{MCl}=$ integrated management of childhood illness $\S$ Pneumonia was ascertained by asking if the child had breathing abnormalities (fast breathing, chest in-drawing or nasal flaring) and/or severe cough. \ All children were assumed to have a history of weight loss/low weight gain.

by calculating the difference between anthropometric measurements at admission and discharge. Means, medians and inter-quartile ranges (IQR) are used to describe and compare continuous parameters. Differences in means were ascertained using Student's t-test and analysis of variance; Kruskall Wallis tests were used to compare medians. Dichotomous variables were compared using $\chi^{2}$ analyses and Fisher's exact test. The sensitivity, specificity, positive predictive value and negative predictive value of different proxy indicators and algorithms for diagnosing 
paediatric HIV infection were also determined using the PC data. The proxy indicators researched are: presence of a chronically ill adult in the household, recent premature death of an adult on the household, female headed household, widow headed household, elderly headed household, child headed household and presence of a tuberculosis infected child or adult[32]. Stepwise logistic regression with backward elimination was used to identify predictors of HIV infection $(\alpha=0.05)$.

Written informed consent was obtained from all study caregivers, usually the mother. The study protocol was approved by the College of Medicine Research and Ethics Committee in Malawi.

\section{Results}

A total of 2,592 children under 5 years of age had participated in the CTC programme prior to the study. Of these, $809(31.2 \%)$ resided outside the study area and were not eligible for the RC. Of the 1783 possible participants, 180 had moved, 69 had died (according to key informants), 113 could not be located due to an improper address and 1,421 were invited to participate [Figure 1]. The cause of

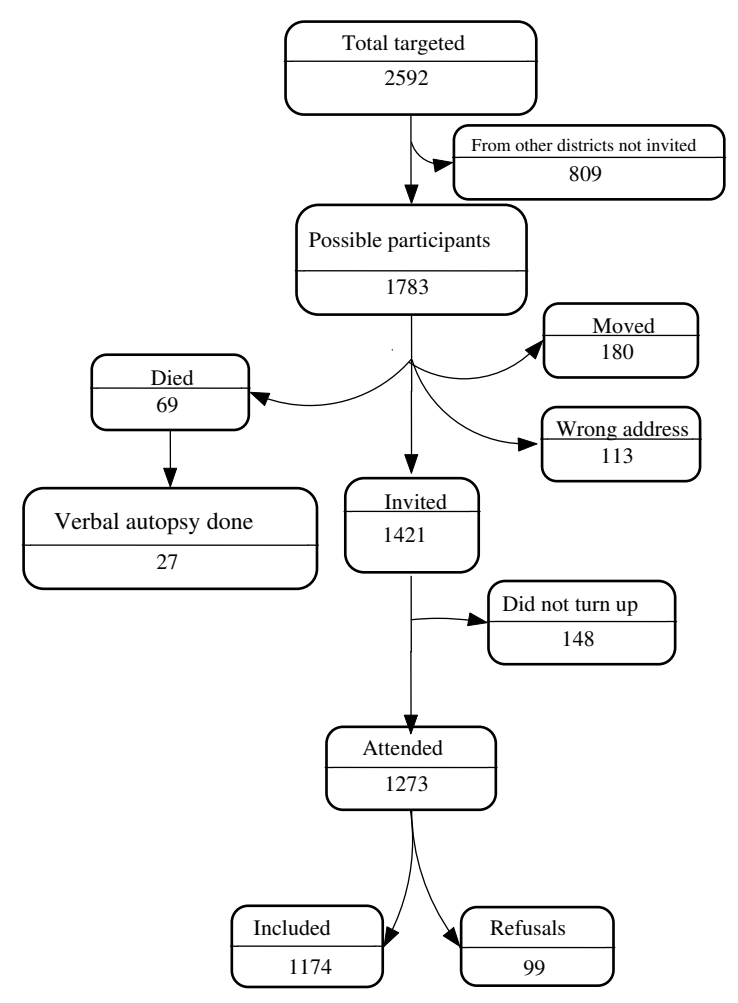

Figure I

Description of the retrospective cohort. death was ascertained for 27 (39\%) of the 69 children that died with the main causes being malaria $(n=8), \operatorname{HIV}(n=$ $7)$, malnutrition $(\mathrm{n}=7)$, and pneumonia $(\mathrm{n}=3)$.

Of the 1421 children invited to participated, 148 (10.4\%) did not turn up. Amongst the returnees, the median time between discharge from the programme and the invitation to participate in the study was 15.6 months (IQR: 10.5-23.3), the average age at CTC admission was 30.0 (17.2) months (median: 26.9; IQR: 17.6 - 37.8) and at study enrolment was 47.2 months (median: 44.3; IQR: 34.4-57. 2). VCT uptake was $92.2 \%(1174 / 1273)$ for children and $58.4 \%(743 / 1273)$ for caregivers. The reasons for refusing the HIV test were: need to consult with husband in $15.2 \%(15 / 99)$ of cases, not psychologically ready in $13.1 \%$ (13/99) of cases, fear of the results in $8.1 \%(8 /$ 99), no authority for allowing testing in $7.1 \%(7 / 99)$, not needed because the child is healthy in $7.1 \%(7 / 99)$, already tested in 5.1\% (5/99) and others (believes already infected or fear of aggravating child anaemia or not willing to cause pain) in $2.0 \%$ of cases (3/99). Thirty-eight caregivers (38.4\% of refusals) did not disclose the reasons for refusal.

735 children were eligible for the PC. The average age at admission was 26.5 (13.7) months (median: 23.0; IQR: 16.9-34.1). VCT uptake was $97 \%$ (714/735) for children and $64.1 \%(471 / 735)$ for parents in this cohort. The reasons for refusal were not collected by study design.

There was no difference in socio-demographic and clinical characteristics at admission between tested and not tested children in either the RC or the PC (data not shown).

Other baseline characteristics of children in the RC and PC groups are shown in Table 2. Family history of tuberculosis (TB) was more common RC $(\mathrm{p}<0.01)$. Only 22 PC children (3.1\%) and 29 RC children $(2.5 \%)$ were HIVinfected $(\mathrm{p}=0.45)$. HIV prevalence was similar amongst parents in both cohorts. Amongst caregivers tested, 5.4\% (58/1081) of mothers and $2.9 \%$ (3/133) of fathers were HIV-infected giving an overall prevalence amongst caregivers of $5.0 \%(61 / 1214)$.

In both RC and PC cohorts, there was no significant difference in the sex ratio, age distribution and in frequency of family history of tuberculosis among HIV-infected and HIV-negative children (Table 3). HIV-infected children were more likely to be orphaned and to come from a household with at least one HIV proxy indicator (Table 3). Nutritional status at admission differed between HIVinfected and HIV-uninfected children (Table 4). HIVinfected children were more likely to be admitted with MUAC $<110 \mathrm{~mm}$ and less likely to have oedema than uninfected children in both cohorts. Oedematous malnu- 
Table 2: Baseline characteristics of participants in the retrospective and prospective cohorts

\begin{tabular}{|c|c|c|c|c|c|c|c|c|}
\hline & \multicolumn{3}{|c|}{ Prospective } & \multicolumn{3}{|c|}{ Retrospective } & \multicolumn{2}{|c|}{ Total } \\
\hline & $\mathbf{n}$ & $\%$ & mean (SD) & $\mathbf{n}$ & $\%$ & mean(SD) & $\mathbf{N}$ & $\%$ \\
\hline \multicolumn{9}{|l|}{ VCT uptake } \\
\hline Accepted VCT & 714 & 97.1 & & 1174 & 92.2 & & 1888 & 94.0 \\
\hline Refused VCT & 21 & 2.9 & & 99 & 7.8 & & 120 & 6.0 \\
\hline Total & 735 & 100.0 & & 1273 & 100.0 & & 2008 & 100.0 \\
\hline \multicolumn{9}{|l|}{ Parents testing uptake } \\
\hline Parent and child tested & 471 & 66.0 & & 743 & 63.3 & & 1214 & 64.3 \\
\hline Only child tested & 243 & 34.0 & & 431 & 36.7 & & 674 & 35.7 \\
\hline Total & 714 & 100.0 & & 1174 & 100.0 & & 1888 & 100.0 \\
\hline \multicolumn{9}{|l|}{ Parents' vital status } \\
\hline Orphan (I or both parents dead) & 35 & 5.0 & & 100 & 8.6 & & 135 & 7.3 \\
\hline Both parents alive & 661 & 95.0 & & 1065 & 91.4 & & 1726 & 92.7 \\
\hline Total & 696 & 100.0 & & 1165 & 100.0 & & $|86|$ & 100.0 \\
\hline \multicolumn{9}{|l|}{ Family history of TB } \\
\hline Yes & 65 & 9.1 & & 127 & 19.1 & & 192 & 13.9 \\
\hline No & 648 & 90.9 & & 539 & 80.9 & & 1187 & 86.1 \\
\hline Total & 713 & 100.0 & & 666 & 100.0 & & 1379 & 100.0 \\
\hline \multicolumn{9}{|l|}{ Sex } \\
\hline Female & 353 & 49.4 & & 595 & 52.4 & & 948 & 51.3 \\
\hline Male & 361 & 50.6 & & 540 & 47.6 & & 901 & 48.7 \\
\hline Total & 714 & 100.0 & & 1135 & 100.0 & & 1849 & 100.0 \\
\hline \multicolumn{9}{|l|}{ Age (months) } \\
\hline$<12$ & 62 & 10.5 & & 157 & 16.8 & & 219 & 14.4 \\
\hline $12-<24$ & 272 & 46.1 & & 354 & 37.9 & & 626 & 41.1 \\
\hline $24-<36$ & 153 & 25.9 & & 275 & 29.5 & & 428 & 28.1 \\
\hline$>=36$ & 103 & 17.5 & & 147 & 15.8 & & 250 & 16.4 \\
\hline Total & 590 & 100.0 & & 933 & 100.0 & & 1523 & 100.0 \\
\hline \multicolumn{9}{|l|}{ Admission category } \\
\hline Oedema & 597 & 83.7 & & 659 & 67.4 & & 1256 & 74.3 \\
\hline Maramus & 51 & 7.2 & & 160 & 16.4 & & 211 & 12.5 \\
\hline MUAC $<110 \mathrm{~mm}$ & 46 & 6.5 & & 75 & 7.7 & & 121 & 7.2 \\
\hline Other criteria & 19 & 2.7 & & 84 & 8.6 & & 103 & 6.1 \\
\hline Total & 713 & 100.0 & & 978 & 100.0 & & 1691 & 100.0 \\
\hline \multicolumn{9}{|l|}{ Presence of oedema } \\
\hline Yes & 597 & 83.7 & & 659 & 67.4 & & 1256 & 74.3 \\
\hline No & 116 & 16.3 & & 319 & 32.6 & & 435 & 25.7 \\
\hline Total & 713 & 100.0 & & 978 & 100.0 & & 1691 & 100.0 \\
\hline WHM \% (SD) & & & $83.3(13.0)$ & & & $84.2(14.4)$ & & \\
\hline$>=80$ & 397 & 58.7 & & 552 & 59.9 & & 949 & 59.4 \\
\hline 70 to $<80 \%$ & 187 & 27.6 & & 186 & 20.2 & & 373 & 23.3 \\
\hline$<70 \%$ & 93 & 13.7 & & 183 & 19.9 & & 276 & 17.3 \\
\hline Total & 677 & 100.0 & & 921 & 100.0 & & 1598 & 100.0 \\
\hline MUAC (SD) & & & $118.0(16.9)$ & & & $119.2(18.9)$ & & \\
\hline$>=125 \mathrm{~mm}$ & 219 & 34.9 & & 326 & 42.0 & & 545 & 38.8 \\
\hline 110 to $<125 \mathrm{~mm}$ & 223 & 35.5 & & 208 & 26.8 & & 431 & 30.7 \\
\hline$<110 \mathrm{~mm}$ & 186 & 29.6 & & 242 & 31.2 & & 428 & 30.5 \\
\hline Total & 628 & 100.0 & & 776 & 100.0 & & 1404 & 100.0 \\
\hline
\end{tabular}

trition, however, was the most frequent admission characteristic in both infected and uninfected children. An equal proportion of HIV-positive $(8 / 22=36.4 \%)$ and HIV-negative children $(249 / 692=36.0 \%)$ required inpatient stabilisation prior to referral to OTP ( $\mathrm{p}=0.971)$. About onethird of all HIV-positive children were orphaned (at least one parent dead) compared with $<10 \%$ of HIV-negative children ( $\mathrm{p}<0.001$ in both cohorts).
Nutritional recovery also varied by HIV status (Table 4). In the PC, 13 HIV-infected children (59.1\%) and 523 HIV-uninfected $(83.4 \%)$ achieved discharge WFH ( $\mathrm{p}=$ 0.003 ). Average rate of weight gain was $4.7 \mathrm{~g} / \mathrm{kg} /$ day in uninfected children and $2.8 \mathrm{~g} / \mathrm{kg} / \mathrm{d}$ in HIV-positive PC children. Median recovery time to discharge was 42 days for uninfected children and 56 days for HIV-positive children. Five HIV-positive children (22.7\%) and 89 HIV-neg- 
Table 3: Demographic characteristics, tuberculosis history and nutrition admission criteria according to the HIV status of children from retrospective and prospective cohorts.

\begin{tabular}{|c|c|c|c|c|c|c|c|c|c|c|}
\hline \multirow[b]{3}{*}{ Variable } & \multicolumn{4}{|c|}{ Prospective } & \multirow[t]{3}{*}{ p-value } & \multicolumn{4}{|c|}{ Retrospective } & \multirow[t]{3}{*}{ p-value } \\
\hline & \multicolumn{2}{|c|}{ HIV+ve } & \multicolumn{2}{|c|}{ HIV-ve } & & \multicolumn{2}{|c|}{ HIV+ve } & \multicolumn{2}{|c|}{ HIV-ve } & \\
\hline & $\mathbf{n}$ & $\%$ & $\mathbf{n}$ & $\%$ & & $\mathbf{n}$ & $\%$ & $\mathbf{n}$ & $\%$ & \\
\hline \multicolumn{11}{|l|}{ Sex } \\
\hline Female & 12 & 54.5 & 341 & 49.3 & & 15 & 53.6 & 580 & 52.4 & \\
\hline Male & 10 & 45.5 & 351 & 50.7 & 0.626 & 13 & 46.4 & 527 & 47.6 & 0.902 \\
\hline Total & 22 & 100.0 & 692 & 100.0 & & 28 & 100.0 & 1107 & 100.0 & \\
\hline \multicolumn{11}{|l|}{ Age } \\
\hline$<12$ & 5 & 25.0 & 57 & 10.0 & & 4 & 16.0 & 153 & 16.9 & \\
\hline $12-<24$ & 6 & 30.0 & 266 & 46.7 & & 9 & 36.0 & 345 & 38.0 & \\
\hline $24-<36$ & 4 & 20.0 & 149 & 26.1 & 0.099 & 8 & 32.0 & 267 & 29.4 & 0.993 \\
\hline$>=36$ & 5 & 25.0 & 98 & 17.2 & & 4 & 16.0 & 143 & 15.7 & \\
\hline Total & 20 & 100.0 & 570 & 100.0 & & 25 & 100.0 & 908 & 100.0 & \\
\hline \multicolumn{11}{|l|}{ Parents status } \\
\hline Orphan (I or both parents) & 7 & 31.8 & 28 & 4.2 & & 10 & 34.5 & 90 & 7.9 & \\
\hline Parents alive & 15 & 68.2 & 646 & 95.8 & $<0.001$ & 19 & 65.5 & 1046 & 92.1 & $<0.001$ \\
\hline Total & 22 & 100.0 & 674 & 100.0 & & 29 & 100.0 & 1136 & 100.0 & \\
\hline \multicolumn{11}{|l|}{ Presence of proxy indicator } \\
\hline$>=1$ proxy present & 14 & 66.7 & 138 & 21.5 & & 15 & 53.6 & 261 & 23.9 & \\
\hline None & 7 & 33.3 & 505 & 78.5 & $<0.001$ & 13 & 46.4 & 832 & 76.1 & $<0.001$ \\
\hline Total & 21 & 100.0 & 643 & 100.0 & & 28 & 100.0 & 1093 & 100.0 & \\
\hline \multicolumn{11}{|c|}{ Family history of tuberculosis } \\
\hline Yes & 4 & 19.0 & 54 & 8.0 & & 7 & 29.2 & 120 & 18.7 & \\
\hline No & 17 & 81.0 & 621 & 92.0 & 0.089 & 17 & 70.8 & 522 & 81.3 & 0.193 \\
\hline Total & 21 & & 675 & 100.0 & & 24 & 100.0 & 642 & 100.0 & \\
\hline \multicolumn{11}{|l|}{ Admission category } \\
\hline oedema & 14 & 63.6 & 583 & 84.4 & & 16 & 55.2 & 643 & 67.8 & \\
\hline No oedema & 8 & 36.4 & 108 & 15.6 & 0.017 & 13 & 44.8 & 306 & 32.2 & 0.017 \\
\hline Total & 22 & 100.0 & 691 & 100.0 & & 29 & 100.0 & 949 & 100.0 & \\
\hline
\end{tabular}

ative children (14.2\%) defaulted from the programme (p $<0.001)$. Four HIV-positive children died during the CTC treatment $(18.2 \%)$; mortality amongst uninfected children was $1.8 \%(\mathrm{p}<0.001)$. Estimated daily weight gain was lower in the RC children, in part due to the high prevalence of oedema at admission and use of admission weight to estimate this parameter.

Nutritional status at follow-up varied according to HIV status. Approximately 15 months after discharge, 24 out of 28 (85.7\%) HIV-infected RC children were not malnourished (WFH $>80 \%$ reference median and no bilateral pitting oedema). However, six of these children had a MUAC below $125 \mathrm{~mm}$, including one with a MUAC $<110$ $\mathrm{mm}$, giving an overall malnutrition rate of $35.7 \%$ (10 out of 28) in HIV-infected children compared with a malnutrition rate of $2.0 \%(22 / 1094)$ in HIV-negative children ( $p$ $=0.001$ ).

The predictive characteristics for variables included in clinical algorithms, for individual proxy indicators, and for the 3 algorithms presently used to diagnose paediatric HIV are shown in Table 5. All three of the clinical algorithms had positive likelihood ratio lower than 10 and negative likelihood ratio higher than 0.1 suggesting limited utility for ruling-out and ruling in paediatric HIV. The presence of one or more HIV proxy indicators in combination with MUAC $<110 \mathrm{~mm}$ was also a poor predictor of the presence of an HIV infection. In contrast, however, severely malnourished children with a MUAC $>110 \mathrm{~mm}$ and no proxy indicators were 10 -fold less likely to be HIVinfected, suggesting that this combination may be useful for ruling out HIV where confirmatory paediatric testing is not widely available. The other criteria with high positive likelihood for predicting HIV (i.e., PLR > 10) are having a deceased father or living in a widow-headed household.

\section{Discussion}

The study aims were to assess whether a CTC programme can be used as an entry point for HIV services, including HIV testing and treatment of malnutrition in HIV-positive children, and to compare outcomes of HIV-positive and HIV-negative children within the programme. More than half of the HIV-infected children in the PC (59.1\%) recovered to a satisfactory nutritional status using CTC protocols, suggesting that SAM can be managed in the community for many HIV-infected children. Furthermore, about two-thirds of the infected children identified after 
Table 4: Nutritional status at enrolment and the impact of CTC in HIV-positive and HIV-negative children

\begin{tabular}{|c|c|c|c|c|c|c|}
\hline & \multicolumn{3}{|c|}{ HIV positive } & \multicolumn{2}{|r|}{ HIV negative } & \multirow[t]{2}{*}{ P-value } \\
\hline & $\mathbf{n}$ & $\%$ & & $\mathbf{n}$ & $\%$ & \\
\hline \multicolumn{7}{|l|}{$\begin{array}{l}\text { Prospective cohort } \\
\text { Admission category }\end{array}$} \\
\hline Oedema & 14 & 63.6 & & 583 & 84.4 & $0.017 \dagger$ \\
\hline Maramus & 1 & 4.5 & & 50 & 7.2 & \\
\hline MUAC $<110 \mathrm{~mm}$ & 5 & 22.7 & & 41 & 5.9 & \\
\hline Others criteria & 2 & 9.2 & & 17 & 2.5 & \\
\hline Total & 22 & 100.0 & & 691 & 100.0 & \\
\hline WHM\% mean(SD) & & & $80.5(8.9)$ & & $83.3(12.6)$ & 0.3 \\
\hline$>=70 \%$ & 20 & 90.9 & & 564 & 86.1 & 0.755 \\
\hline$<70 \%$ & 2 & 9.1 & & 91 & 13.9 & \\
\hline Total & 22 & 100.0 & & 655 & 100.0 & \\
\hline MUAC mean (SD) & & & $109.2(16.4)$ & & $118.3(16.9)$ & 0.025 \\
\hline$>=110 \mathrm{~mm}$ & 7 & 38.9 & & 435 & 71.3 & 0.003 \\
\hline$<110 \mathrm{~mm}$ & II & 61.1 & & 175 & 28.7 & \\
\hline Total & 18 & 100.0 & & 610 & 100.0 & \\
\hline \multicolumn{7}{|l|}{ CTC Outcomes } \\
\hline Recovered & 13 & 59.1 & & 523 & 83.4 & 0.002 \\
\hline Defaulted & 5 & 22.7 & & 89 & 14.2 & $<0.001$ \\
\hline Died & 4 & 18.2 & & 11 & 1.8 & $<0.001$ \\
\hline Transfer or still in programme & & & & 4 & 0.7 & - \\
\hline Median weight gain (IQR) g/kg/day & 20 & & $2.8(1.3-3.9)$ & 614 & $4.7(2.9-6.7)$ & 0.007 \\
\hline Median MUAC change (IQR) mm/day & 9 & & $0.11(-0.03-0.31)$ & 361 & $0.21(0.05-0.39)$ & 0.223 \\
\hline Median LoS (IQR) days & 20 & & $56(36-68)$ & 622 & $42(28-63)$ & 0.25 \\
\hline \multicolumn{7}{|l|}{ Retrospective cohort } \\
\hline \multicolumn{7}{|l|}{ Admission category } \\
\hline Oedema & 16 & 55.2 & & 643 & 67.8 & $0.154 \dagger$ \\
\hline Marasmus & 6 & 20.7 & & 154 & 16.2 & \\
\hline MUAC $<110 \mathrm{~mm}$ & 5 & 17.2 & & 70 & 7.4 & \\
\hline Others criteriał & 2 & 6.9 & & 82 & 8.6 & \\
\hline Total & 29 & 100.0 & & 949 & 100.0 & \\
\hline WHM\% (SD) & & & $81.0(15.7)$ & & $84.3(14.4)$ & 0.26 \\
\hline$>=70$ & 17 & 68.0 & & 721 & 80.5 & 0.130 \\
\hline$<70 \%$ & 8 & 32.0 & & 175 & 19.5 & \\
\hline Total & 25 & 100.0 & & 896 & 100.0 & \\
\hline \multicolumn{7}{|l|}{ CTC Outcomes } \\
\hline Median Weight gain (IQR) g/kg/day & 24 & & $2.2(1.6-4.0)$ & 880 & $3.1(1.1-5.9)$ & 0.309 \\
\hline Median MUAC change (IQR)mm/day & II & & $0.22(0.01-0.45)$ & 476 & $0.25(0.03-0.48)$ & 0.891 \\
\hline Median LOS (IQR) days & 25 & & $63(42-128)$ & 912 & $42(28-67)$ & 0.002 \\
\hline
\end{tabular}

† Comparison \% oedematous malnutrition; $\ddagger$ others criteria $=$ age above 6 months and weight less than $4 \mathrm{~kg}$, child with visible wasting but not meeting marasmus and MUAC criteria and less than 6 months children.

discharge were still adequately nourished. This nutritional recovery occurred without use of antiretroviral therapy (ART), suggesting that severe malnutrition was primarily the result of semi-starvation among recovering study children. These findings are different from those normally observed in developed and middle income countries where severe malnutrition in HIV-positive children is typically caused by HIV-related metabolic disturbances, which do not improve without ART [42]. Indeed, the poor response to nutritional intervention of cachexia, a form of malnutrition that is primarily due to chronic systemic inflammation is a well-known phenomenon $[43,44]$.

The 59.1\% recovery rate for HIV-infected children observed in the PC arm of our study includes deaths in both the inpatient-based stabilisation phase and the out- 
Table 5: The prevalence and diagnostic characteristics of proxy indicators and clinical algorithms for identifying HIV infection in severely malnourished children

Prevalence

(\%)
OR Sensitivity Specificity PPV $\dagger$ NPV $\ddagger$ PLR $\$$ NLR\&

$(95 \% \mathrm{Cl})$
(\%)

\begin{tabular}{|c|c|c|c|c|c|c|c|c|}
\hline \multicolumn{9}{|l|}{$\begin{array}{l}\text { Individual proxy indicators, symptoms } \\
\text { and signs }\end{array}$} \\
\hline From widow headed household & 1.4 & $30.0(7.4-121.6)$ & 19 & 99.2 & 44.4 & 97.4 & 23.8 & 0.8 \\
\hline Looked after by grand-mother & 4.1 & $4.1(1.1-14.6)$ & 13.6 & 96.3 & 10.7 & 97.1 & 3.7 & 0.9 \\
\hline Orphan (one or both parents dead) & 5.0 & $10.8(4.1-28.5)$ & 31.8 & 95.8 & 20 & 97.7 & 7.6 & 0.7 \\
\hline From female headed household & 7.1 & $5.8(2.1-17.2)$ & 28.6 & 93.6 & 12.8 & 97.6 & 4.5 & 0.8 \\
\hline \multicolumn{9}{|l|}{ Symptoms and signs used in algorithms } \\
\hline Child with tuberculosis & 1.4 & $9.2(1.8-47.7)$ & 10 & 98.8 & 20 & 97.4 & 8.3 & 0.9 \\
\hline Minor muco-cutaneous manifestations & 7.2 & $4.6(1.6-13.2)$ & 25 & 93.3 & 10 & 97.6 & 3.7 & 0.8 \\
\hline \multicolumn{9}{|l|}{$\begin{array}{l}\text { Variables associated with HIV in the } \\
\text { present study }\end{array}$} \\
\hline Death of the father & 3.1 & 15.6(4.7-49.9) & 27.3 & 97.6 & 27.3 & 97.6 & 11.4 & 0.7 \\
\hline Age $<12$ months or age $>59$ months & 13.6 & $3.7(1.4-9.5)$ & 35 & 85.2 & 8.8 & 97.5 & 2.4 & 0.8 \\
\hline MUAC $<110 \mathrm{~mm}$ & 29.6 & $3.5(1.9-10.2)$ & 61.1 & 71.3 & 5.9 & 98.4 & 2.1 & 0.5 \\
\hline Absence of oedema & 17.1 & $2.9(1.1-7.7)$ & 36.4 & 83.7 & 8.3 & 93 & 2.2 & 0.8 \\
\hline Axillary nodes enlargement & 4.8 & $6.7(1.7-26.4)$ & 23.1 & 95.7 & 13.6 & 97.7 & 5.4 & 0.8 \\
\hline \multicolumn{9}{|l|}{ Algorithm and combinations } \\
\hline $\begin{array}{l}\text { South-African IMCI modified algorithm for } \\
\text { paediatric HIV diagnosis }\end{array}$ & & & 20.0 & 94.5 & 8.7 & 97.8 & 3.6 & 0.8 \\
\hline Original IMCl algorithm & & & 9.1 & 96.7 & 8.0 & 97.1 & 2.8 & 0.9 \\
\hline Action Against Hunger algorithm & & & 60.0 & 62.1 & 3.5 & 98.3 & 1.6 & 0.6 \\
\hline $\begin{array}{l}\text { Presence one or more proxy indicators a } \\
\mathrm{mm}\end{array}$ & 10 & & 95.5 & 54.5 & 7.1 & 99.7 & 2.1 & 0.1 \\
\hline
\end{tabular}

$\dagger P P V=$ positive predictive value; $\ddagger N P V=$ Negative predictive value; $\S P L R=$ likelihood ratio for a positive test; \& NLR = likelihood ratio for a negative test

patient-based recovery phase of care. This figure is similar to the $56 \%$ recovery rate reported in a study in southern Malawi where RUTF was used for Home Therapy (HT) in the recovery phase of care, after patients had been discharged from a hospital Nutrition Rehabilitation Unit (NRU) [18]. As mortality amongst severely malnourished HIV-positive children is usually highest during the initial phase of treatment and may exceed 30\% [45], the results from our study are encouraging.

It is possible that our improved recovery rates arise from the decentralised nature of the CTC model of care that is designed to remove barriers to access and promote early presentation before serious complications develop. However, the numbers of HIV subjects in our PC are small and these findings need to be confirmed by larger studies. The results of the present study are also encouraging when compared with the 3-month mortality rate of $42.9 \%$ among severely wasted (WFH $<70 \%$ ) children started on ART, recently reported in Malawi [46]. Mortality in this group was $>10$-fold higher than among children starting on ART who were not acutely malnourished (WFH > $80 \%)$ [46].
As observed in other nutritional studies carried out in Malawi, the HIV-positive children in our cohorts recovered more slowly than the HIV-negative children $[18,45]$. The possible reasons for slower weight gain include reduced intake due to poor appetite, nutrient malabsorption, increased incidence of infections that were unresponsive to the broad-spectrum antibiotics used, and increased nutrient requirements due to HIV [47]. Despite the possibility of reduced appetite especially at the beginning of treatment, we believe that HIV-positive children may need more RUTF than HIV-negative children to achieve similar growth rates and improvements in other nutritional indices. Increasing the amount of daily energy offered to HIV infected children may improve their weight gain and reduce the length of stay in the program, and further testing of this hypothesis is needed. Continued nutritional surveillance and supplementation after discharge may also help HIV-infected children to remain well-nourished. Reducing recovery time and subsequent length and cost of program participation will reduce default rates, which occurred, on average, after 56 days by families with all HIV-positive children but at 70 days for those who finally defaulted. Similarly, adapting CTC routine antibiotic treatment to the epidemiology of HIV-associated 
infections and inclusion of routine prophylactic cotrimoxazole for HIV-positive children, as currently recommended by $\mathrm{WHO}$, may improve recovery in this group $[1,48]$.

The low relapse rates following CTC is in contrast to NRU and other outpatient SAM treatment programmes where morbidity and mortality after discharge are high [49-51]. Although survival bias cannot be ruled out as an explanation for this finding, it is possible that the CTC design, which uses community mobilization and referral for early identification and treatment of SAM also improves longterm recovery compared to hospital-based treatment programmes. SAM is a progressive condition and prognosis is directly associated with the lead time to presentation and treatment. Initiating nutritional intervention as soon as SAM presents may be especially important for HIVinfected and exposed children.

The high VCT uptake for adults and children, the low HIVprevalence amongst SAM children, and the low nutritional relapse rate amongst surviving HIV-positive and uninfected children over a year after discharge are all noteworthy in our study. The high VCT uptake is comparable to that observed recently in some NRUs in Malawi [16] but contrasts with anecdotal reports of reluctance to come forward for HIV testing offered by clinics and therapeutic feeding programmes. We believe that the "opt-out" approach used in this study, with HIV testing offered to everyone with the right to refuse rather than the standard "opt-in" approach where people have to specifically request HIV testing, contributed to the high uptake seen here $[11,52,53]$. We also believe that offering testing through a programme such as CTC that is well established in the community improves trust and reduces the fear of stigmatization. Caregivers were informed about the opportunity for HIV testing one week prior to travelling to the health centre and no substantial compensation was offered, ruling out the likelihood of coercion in the RC. The high uptake observed here suggests that CTC is a potentially innovative way to increase access to and coverage of HIV testing, particularly in rural areas [54]. It is important to note however that CTC would have to be combined with other community based HIV testing and counselling approaches like the home based and mobile VCT in order to obtain good coverage; in prior studies we observed that only $16 \%$ of HIV-affected households has a malnourished child treated in the CTC programme in the past 18 months $[9,55,56]$.

There are a number of factors that are likely to have contributed to the low prevalence of HIV amongst severely malnourished children in this study. Chronic food insecurity, frequent common childhood illnesses, poor access to modern health care and suboptimal complementary feed- ing practices all cause SAM in the absence of HIV in Malawi [57-59]. The decentralised nature and the high coverage rates obtained by CTC programmes means that a higher proportion of admissions live in remote rural areas far from towns and main roads [60] in contrast to admissions in more centrally located urban hospital units. People from rural areas are all subsistence farmers, have poor income and low educational level and have no possibility for travelling within or outside the country. These factors are known to increase the prevalence of malnutrition and lower that of HIV [57,61-64]. Lastly, the low HIV prevalence might also be explained by the high mortality of HIV infected infants biasing our data to include those children who have survive infancy. Without effective treatment, it is estimated that over 50\% of infants who acquired HIV infection through mother-to-child transmission will die by two years of age (compared to $8 \%$ of uninfected children) while in Malawi kwashiorkor, the most common form of SAM in children, peaks between 18 to 23 months of age [65-68]. The relatively older average ages of children in both the PC (26.4 months) and RC cohorts (47.2 months), suggests the possibility of survival bias.

Our estimated adult HIV prevalence of $5.0 \%$ is predictably lower than the antenatal HIV prevalence rate in the central region $(9.8 \%)$ but similar to comparable adult prevalence rates of $6.4 \%$ and $4.1 \%$ for the region and for an adjacent district, respectively, as reported in the 2004 Malawi Demographic and Health Survey $[69,70]$. Our study suggests that targeting adult caretakers of malnourished children for HIV testing is feasible but additional outreach and counseling efforts may be needed to increase uptake.

Our analysis confirms that clinical algorithms designed to diagnose paediatric HIV are neither sufficiently sensitive nor specific in severely malnourished children and that blood tests are therefore required to confirm the diagnosis [71]. In context where blood tests are not available, the combination of MUAC $>110 \mathrm{~mm}$ and absence of proxy indicators can be used to rule out the presence of HIV. These family history variables could be incorporated into future CTC protocols for confirmed or suspected paediatric HIV in setting without possibility of blood tests [72].

SAM is one of several criteria for initiating ART in HIVpositive children [73]. The fact that some previously undiagnosed HIV-positive children recovered from malnutrition, and were still healthy and asymptomatic an average of 15 months after discharge from CTC without ART, suggests that the presence of malnutrition should not be the sole criteria for initiating ART in food insecure settings. One possibility is that initiation of ART could be reserved for children who do not respond to CTC or at least could be delayed until nutrition improvement to minimize 
antiretroviral side effects. Several studies have reported that HIV-infected children tend to develop marasmus rather than kwashiorkor and that CD4 count remains higher in HIV-infected children with kwashiorkor compared to those with marasmus $[17,74,75]$. Therefore, delayed initiation of ART could be considered for children with kwashiorkor. This approach could help to prevent unnecessary exposure to ARV drugs that have side effects and toxicity and to reduce the risk of developing resistance [76]. Further research, probably in the form of randomized trials, is urgently needed to strengthen this evidence base before any change of practice is recommended.

Several limitations of our study deserve mention. This study was carried out in conjunction with an ongoing CTC programme and clinical records were reviewed in order to obtain data on nutritional recovery. Although programme procedures were standardized, we were unable to verify nutritional measurements for accuracy. As noted previously, the RC may be subject to survival bias, and therefore we have limited our use and interpretation of the RC data. The statistical power of these analyses is also limited by the small number of HIV-positive children in the study and by further reduction of the sample size due to missing data for age and nutritional status. Nevertheless, the data from both cohorts paint a consistent picture with regard to the potential positive impact of Community-based Therapeutic Care for managing SAM in HIV-positive and uninfected children in rural Africa.

\section{Conclusion}

The results of the present study demonstrate that CTC is a valuable entry point for HIV testing for severely malnourished children and that good recovery rates can be achieved in HIV-infected severely malnourished children admitted to the program. These results indicate that CTC can be used to improve the coverage of HIV services, especially in rural areas. The approach has several important advantages over traditional inpatient therapeutic care, including earlier intervention, greater coverage, and increased accessibility. All of these characteristics are particularly important for providing timely care to HIVexposed and vulnerable children. Additional research on feeding protocols for HIV-infected children and on timing of ART initiation are needed to refine CTC protocols in settings where HIV is common.

\section{Competing interests}

The authors Paluku Bahwere, Kate Sadler, Saul Guerrero and Steve Collins work for Valid International, an organisation that has been engaged in the research and development of Community-based Therapeutic Care. Dr Steve Collins is also unpaid director of Valid Nutrition, a notfor-profit company established to research and manufacture ready-to-use therapeutic food in developing coun- tries. There is no conflicting interest for all the other authors.

\section{Authors' contributions}

PB: concept and design of the research, data collection, data analysis and interpretation, drafting of the paper. EP: concept and design of the research, critical revision of paper content. MCJ: data collection, analysis of data and revision of the manusdcript. KS: concept and design of the research, data analysis and interpretation, revision of the draft of the paper. CHGT: concept and design of the research, critical revision of paper content. SG: design and concept of the research, data collection and revision of the manuscript. SC: concept and design of the research, data analysis and interpretation, revision of the draft of the paper. All authors read and approved the final manuscript.

\section{Acknowledgements}

The authors would like to acknowledge the invaluable assistance of the Ministry of Health clinic staff in Dowa District and all the CTC programme beneficiaries and their families. Funding for this paper was provided by the Bureau for Africa, Office of Sustainable Development of the United States Agency for International Development (USAID) under the terms of Contract AOT-C-00-99-00237-00 and Food and Nutrition Technical Assistance (FANTA).

\section{References}

I. Chintu C, Bhat GJ, Walker AS, Mulenga V, Sinyinza F, Lishimpi K, et al.: Co-trimoxazole as prophylaxis against opportunistic infections in HIV-infected Zambian children (CHAP): a double-blind randomised placebo-controlled trial. Lancet 2004, 364: $1865-187 \mid$.

2. Gibb DM, Duong T, Tookey PA, Sharland M, Tudor-Williams G, Novelli V, et al:: Decline in mortality, AIDS, and hospital admissions in perinatally HIV-I infected children in the United Kingdom and Ireland. BMJ 2003, 327:1019.

3. Judd A, Doerholt K, Tookey PA, Sharland M, Riordan A, Menson E, et al.: Morbidity, mortality, and response to treatment by children in the United Kingdom and Ireland with perinatally acquired HIV infection during 1996-2006: planning for teenage and adult care. Clin Infect Dis 2007, 45:918-924.

4. Sanchez JM, Ramos Amador JT, Fernandez dM, Gonzalez Tomee MI, Rojo CP, Ferrnado VP, et al.: Impact of highly active antiretroviral therapy on the morbidity and mortality in Spanish human immunodeficiency virus-infected children. Pediatr Infect Dis J 2003, 22:863-867.

5. Walker AS, Mulenga V, Ford D, Kabamba D, Sinyinza F, Kankasa C, et al.: The impact of daily cotrimoxazole prophylaxis and antiretroviral therapy on mortality and hospital admissions in HIV-infected Zambian children. Clin Infect Dis 2007, 44: $136 \mid-1367$.

6. UNAIDS: UNAIDS policy position on HIV testing and counselling. UNAIDS 2006. Ref Type: Report

7. Prendergast A, Tudor-Williams G, Jeena P, Burchett S, Goulder P: International perspectives, progress, and future challenges of paediatric HIV infection. Lancet 2007, 370:68-80.

8. Qazi SA, Muhe LM: Integrating HIV management for children into the Integrated Management of Childhood IIIness guidelines. Trans R Soc Trop Med Hyg 2006, 100:10-13.

9. Were WA, Mermin JH, Wamai N, Awor AC, Bechange S, Moss S, et al.: Undiagnosed HIV infection and couple HIV discordance among household members of HIV-infected people receiving antiretroviral therapy in Uganda. J Acquir Immune Defic Syndr 2006, 43:91-95. 
10. De Cock KM, Bunnell R, Mermin J: Unfinished business - expanding HIV testing in developing countries. N Engl J Med 2006, 354:440-442.

I I. Manzi M, Zachariah R, Teck R, Buhendwa L, Kazima J, Bakali E, et al.: High acceptability of voluntary counselling and HIV-testing but unacceptable loss to follow up in a prevention of motherto-child HIV transmission programme in rural Malawi: scaling-up requires a different way of acting. Trop Med Int Health 2005, 1 0: 1242-1250.

12. Anonymous: Antiretroviral therapy for children in the routine setting in Malawi. Trans R Soc Trop Med Hyg 2007, 10 I:5 II-5I6.

13. Kessler L, Daley H, Malenga G, Graham S: The impact of the human immunodeficiency virus type $I$ on the management of severe malnutrition in Malawi. Ann Trop Paediatr 2000, 20:50-56.

14. Zaba B, Whitworth J, Marston M, Nakiyingi J, Ruberantwari A, Urassa $M$, et al.: HIV and mortality of mothers and children: evidence from cohort studies in Uganda, Tanzania, and Malawi. Epidemiology 2005, 16:275-280.

15. Rogerson SR, Gladstone M, Callaghan M, Erhart L, Rogerson S], Borgstein $\mathrm{E}$, et al:: HIV infection among paediatric in-patients in Blantyre, Malawi. Trans R Soc Trop Med Hyg 2004, 98:544-552.

16. Thurstans S, Kerac M, Maleta K, Banda T, Nesbit A: HIV point-prevalence amongst malnourished children admitted to nutritional rehabilitation units in Malawi: geographical \& seasonal variations. AIDS 2006.XVI International AIDS conference Toronto, Canada 2006. 13-18 August 2006: abstract MOPE0236. Ref Type: Abstract

17. Ticklay IM, Nathoo KJ, Siziya S, Brady JP: HIV infection in malnourished children in Harare, Zimbabwe. East Afr Med J 1997, 74:217-220

18. Ndekha MJ, Manary MJ, Ashorn P, Briend A: Home-based therapy with ready-to-use therapeutic food is of benefit to malnourished, HIV-infected Malawian children. Acta Paediatr 2005 , 94:222-225

19. Collins S, Dent N, Binns P, Bahwere P, Sadler K, Hallam A: Management of severe acute malnutrition in children. Lancet 2006 , 368: 1992-2000.

20. Fergusson P, Chikaphupha K, Sitima Y, Chinkhumba J, Bongololo G, Makwiza I, et al.: Family perceptions of quality of care and HIV related stigma in a nutrition rehabilitation unit in Lilongwe, Malawi. AIDS 2006 - XVI International AIDS Conference: Abstract no.WEPE0255" 2006. Ref Type: Abstract

21. Collins S: Community-based therapeutic care: A new paradigm for selective feeding in nutritional crises. London, Humanitarian Practice Network, Overseas Development Institute. Network Paper; 2004:48. Ref Type: Report

22. Briend A, Lacsala R, Prudhon C, Mounier B, Grellety Y, Golden MHN Ready-to-use therapeutic food for treatment of marasmus [letter]. Lancet 1999, 353:1767-1768.

23. Collins S, Yates R: The need to update the classification of acute malnutrition [letter]. Lancet 2003, 362:249.

24. Ministry of Health and Population: Manual for the management of acute severe malnutrition. Lilongwe, Malawi, Government of Malawi 2003. Ref Type: Generic

25. Collins S, Sadler K: The outpatient treatment of severe malnutrition during humanitarian relief programmes. Lancet 2002, 360:1824-1830

26. Ciliberto MA, Sandige H, Ndekha MJ, Ashorn P, Briend A, Ciliberto $\mathrm{HM}$, et al:: Comparison of home-based therapy with ready-touse therapeutic food with standard therapy in the treatment of malnourished Malawian children: a controlled, clinical effectiveness trial. Am J Clin Nutr 2005, 81 : 864-870.

27. Doctor HV, Weinreb AA: Estimation of AIDS adult mortality by verbal autopsy in rural Malawi. AIDS 2003, 17:2509-25I3.

28. Ministry of Health and Population: Treatment of AIDS. The two year plan to scale up antiretroviral therapy in Malawi. Malawi 2004. Ref Type: Report

29. Horwood C, Liebeschuetz S, Blaauw D, Cassol S, Qazi S: Diagnosis of paediatric HIV infection in a primary health care settin with a clinical algorithm. Bull World Health Organ 2003, 8I:858-866.

30. World Health Organisation: Report on the workshop on adaptation of IMCI guidelines to include HIV AIDS Harare. Harare, Zimbabwe 200I. Ref Type: Report
31. Thurstans S: The application of clinical algorithms as tool for the identification of HIV symptomatic malnourished children in the Nutrition Rehabilitation Ubits in Malawi. Action Against Hunger-Malawi 2004. Ref Type: Report

32. Malawi National Vulnerability Assessment Committee, SADC FANR Vulnerability Assessment Committee: Malawi Emergency Food Security Assessment Report. 20-I-2003. Lilongwe, Malawi . Ref Type: Report

33. Valid International: Community-based Therapeutic Care (CTC): A Field Manual Ist edition. Oxford UK: Valid International; 2006.

34. Morley D: Nutritional surveillance of young children in developing countries. Int J Epidemiol | 976, 5:5 I-55.

35. Shakir A, Morley D: Letter: Measuring malnutrition. Lancet I974, I:758-759.

36. De Baets AJ, Edidi BS, Kasali MJ, Beelaert G, Schrooten W, Litzroth $A$, et al:: Pediatric human immunodeficiency virus screening in an African district hospital. Clin Diagn Lab Immunol 2005, I 2:86-92

37. Bobat R, Coovadia H, Coutsoudis A, Moodley D: Determinants of mother-to-child transmission of human immunodeficiency virus type I infection in a cohort from Durban, South Africa. Pediatr Infect Dis J 1996, 15:604-610.

38. Creek T, Tanuri A, Smith M, Seipone K, Smit M, Legwaila K, et al: Early Diagnosis of Human Immunodeficiency Virus in Infants Using Polymerase Chain Reaction on Dried Blood Spots in Botswana's National Program for Prevention of Mother-toChild Transmission. Pediatr Infect Dis J 2008, 27:22-26.

39. Creek TL, Sherman GG, Nkengasong J, Lu L, Finkbeiner T, Fowler $M G$, et al.: Infant human immunodeficiency virus diagnosis in resource-limited settings: issues, technologies, and country experiences. Am J Obstet Gynecol 2007, 197:S64-S7I.

40. CDC: A word processing, database and statistics program for public health on IBM-compatible microcomputers. [6.04]. Atlanta, Centre for Control Disease and Prevention 1995. Ref Type: Computer Program

4I. Norusis MJ: SPSS. In Statistical data analysis Chicago, USA, SPSS Inc; 1990. Ref Type: Computer Program

42. Ball CS: Global issues in pediatric nutrition: AIDS. Nutrition 1998, 14:767-770.

43. Bistrian BR: Dietary treatment in secondary wasting and cachexia. J Nutr 1999, 1 29:290S-294S

44. Kotler DP: Cachexia. Ann Intern Med 2000, 133:622-634

45. Chinkhumba J, Fergusson P, Thurstans S, Nyirenda G, Mafupa H, Tomkins A: Impact of HIV status on pattern of mortality in HIV-infected severely malnourished children, admitted to 3 nutrition rehabilitation units in Central region of Malawi. AIDS2006.XVI International AIDS Conference, Toronto, Canada 13-18 August 2006: Abstract MOAB0405 2006. Ref Type: Abstract

46. Bong CN, Chen SC, Jong YJ, Tok TS, Hsu CF, Schouten EJ, et al.: Outcomes of HIV-infected children with tuberculosis who are started on antiretroviral therapy in Malawi. Int J Tuberc Lung Dis 2007, I I:534-538.

47. World Health Organisation: Nutrient requirements for people living with HIVIAIDS: report of a technical consultation. Geneva 2003. Ref Type: Report

48. Ruffini DD, Madhi SA: The high burden of Pneumocystis carinii pneumonia in African HIV-I-infected children hospitalized for severe pneumonia. AIDS 2002, 16:105-1/2.

49. Pecoul B, Soutif C. Hounkpevi M, Ducos M: Efficacy of a therapeutic feeding centre evaluated during hospitalization and a follow-up period, Tahoua, Niger, 1987-1988. Ann Trop Paediatr 1992, 12:47-54.

50. Reneman L, Derwig J: Long-term prospects of malnourished children after rehabilitation at the Nutrition Rehabilitation Centre of St Mary's Hospital, Mumias, Kenya. J Trop Pediatr 1997, 43:293-296.

5I. Ashworth A: Efficacy and effectiveness of community-based treatment of severe malnutrition. Food Nutr Bull 2006, 27:S24-S48.

52. Bolu OO, Allread V, Creek T, Stringer E, Forna F, Bulterys M, et al: Approaches for scaling up human immunodeficiency virus testing and counseling in prevention of mother-to-child human immunodeficiency virus transmission settings in resource-limited countries. Am J Obstet Gynecol 2007, 197:S83-S89. 
53. Moses A, Zimba C, Kamanga E, Nkhoma J, Maida A, Martinson F, et al.: Prevention of mother-to-child transmission: program changes and the effect on uptake of the HIVNET 012 regimen in Malawi. AIDS 2008, 22:83-87.

54. Office of President and Cabinet: Malawi HIV and AIDS monitoring and Evaluation report 2005: follow up to the declaration of commitment on HIV and AIDS (UNGASS) 2005. Ref Type: Report

55. Bateganya MH, Abdulwadud OA, Kiene SM: Home-based HIV voluntary counseling and testing in developing countries. Cochrane Database Syst Rev 2007:CD006493.

56. Wolff B, Nyanzi B, Katongole G, Ssesanga D, Ruberantwari A, Whitworth J: Evaluation of a home-based voluntary counselling and testing intervention in rural Uganda. Health Policy Plan 2005, 20:109-116.

57. Maleta K, Virtanen SM, Espo M, Kulmala T, Ashorn P: Childhood malnutrition and its predictors in rural Malawi. Paediatr Perinat Epidemiol 2003, 17:384-390.

58. Lin CA, Boslaugh S, Ciliberto HM, Maleta K, Ashorn P, Briend A, et al.: A prospective assessment of food and nutrient intake in a population of Malawian children at risk for kwashiorkor. I Pediatr Gastroenterol Nutr 2007, 44:487-493.

59. Kalanda BF, Verhoeff FH, Brabin BJ: Breast and complementary feeding practices in relation to morbidity and growth in Malawian infants. Eur J Clin Nutr 2006, 60:40 I-407.

60. Sadler K, Myatt M, Feleke T, Collins S: A comparison of the programme coverage of two therapeutic feeding interventions implemented in neighbouring districts of Malawi. Public Health Nutr 2007, 10:907-913.

61. Crampin AC, Glynn JR, Ngwira BM, Mwaungulu FD, Ponnighaus JM, Warndorff DK, et al.: Trends and measurement of HIV prevalence in northern Malawi. AIDS 2003, I7:1817-1825

62. Dallabetta GA, Miotti PG, Chiphangwi JD, Saah AJ, Liomba G, Odaka $\mathrm{N}$, et al.: High socioeconomic status is a risk factor for human immunodeficiency virus type I (HIV-I) infection but not for sexually transmitted diseases in women in Malawi: implications for HIV-I control. J Infect Dis 1993, 167:36-42.

63. Glynn JR, Ponnighaus J, Crampin AC, Sibande F, Sichali L, Nkhosa P, et al:: The development of the HIV epidemic in Karonga District, Malawi. AIDS 200I, 15:2025-2029.

64. Zachariah R, Harries AD, Nkhoma W, Arendt V, Spielmann MP, Buhendwa $L$, et al.: HIV prevalence and demographic risk factors in blood donors. East Afr Med / 2002, 79:88-91.

65. Newell ML, Coovadia H, Cortina-Borja M, Rollins N, Gaillard P, Dabis $\mathrm{F}$ : Mortality of infected and uninfected infants born to HIV. infected mothers in Africa: a pooled analysis. Lancet 2004 364: $1236-1243$

66. Taha TE, Miotti P, Liomba G, Dallabetta G, Chiphangwi J: HIV, maternal death and child survival in Africa. AIDS 1996 10:111-112.

67. Taha TE, Graham SM, Kumwenda NI, Broadhead RL, Hoover DR, Markakis D, et al.: Morbidity among human immunodeficiency virus-I-infected and -uninfected African children. Pediatrics 2000, 106:E77.

68. Courtright $P$, Canner J: The distribution of kwashiorkor in the southern region of Malawi. Ann Trop Paediatr 1995, I5:22I-226.

69. National AIDS Commission: Malawi National HIVIAIDS estimates 2003 Technical report Lilongwe, National AIDS Commission; 2004. Ref Type: Report

70. National Statistical Office (NSO), ORC MACRO: Malawi Demographic and Health Survey 2004. NSO and ORC Macro Calverton, Maryland; 2005. Ref Type: Report

71. Qazi SA, Muhe LM: Integrating HIV management for children into the Integrated Management of Childhood IIIness guidelines. Trans R Soc Trop Med Hyg 2006, 100:10-13.

72. Feinstein AR: Misguided efforts and future challenges for research on "diagnostic tests". J Epidemiol Community Health 2002, 56:330-332

73. World Health Organisation: Antiretroviral therapy of HIV infection in infants and children in resource-limited settings: towards universal access Recommendations for a public Health approach Geneva, Switzerland: World Health Organisation; 2006.

74. Bachou H, Tylleskar T, Downing R, Tumwine JK: Severe malnutrition with and without HIV-I infection in hospitalised children in Kampala, Uganda: differences in clinical features, haematological findings and CD4+ cell counts. Nutr J 2006, 5:27.
75. Beau JP, Imboua-Coulibaly L, Du Lou AD: [The effect of nutritional management on the mortality of malnourished children, uninfected and infected with the human immunodeficiency virus]. Sante 1999, 9:163-167.

76. Kamya MR, Mayanja-Kizza H, Kambugu A, Bakeera-Kitaka S, Semitala $F$, Mwebaze-Songa $P$, et al.: Predictors of long-term viral failure among ugandan children and adults treated with antiretroviral therapy. J Acquir Immune Defic Syndr 2007, 46: I87-193.

\section{Pre-publication history}

The pre-publication history for this paper can be accessed here:

\section{http://www.biomedcentral.com/1471-2334/8/106/pre} pub
Publish with BioMed Central and every scientist can read your work free of charge

"BioMed Central will be the most significant development for disseminating the results of biomedical research in our lifetime. "

Sir Paul Nurse, Cancer Research UK

Your research papers will be:

- available free of charge to the entire biomedical community

- peer reviewed and published immediately upon acceptance

- cited in PubMed and archived on PubMed Central

- yours - you keep the copyright
BioMedcentral 